\title{
The Analysis of Dust Emission in the Life Cycle of Residential Buildings with Different Structures
}

\author{
BIAN Yadong ${ }^{1, a}$, DAI Yanru, ${ }^{2, b}, \mathrm{LI} \mathrm{Li}^{1, \mathrm{c}}$ andHONG Cheng ${ }^{1, \mathrm{~d}}$ \\ ${ }^{1}$ Zhongyuan University of Technology, Zhengzhou, China \\ ${ }^{2}$ Sinohydro Foundation Engineering CO.LTD, Tianjin, China \\ amobcoco@sina.com,,b1162073194@qq.com,clili1993abc@163.com,,hongcheng006@163.com
}

Keywords: Life cycle assessment; Frame structure; Frame shear structure; Residential building; Dust emission

Abstract. Based on the life cycle assessment method and Simapro software, this paper respectively evaluates the life cycle of the frame structure and frame-shear structure of residential buildings in Zhengzhou. The characteristics and differences of architectural dust emission in residential buildings with different structures are compared and analyzed from building material production stage, construction stage, operation stage and dismantling stage. The results indicated that the dust emission of frame structure was higher than that of frame shear structure at all stage, the phenomenon was obvious at building materials production stage where the dust emission respectively reached $12.484 \mathrm{~kg} / \mathrm{m}^{2}$ and $10.635 \mathrm{~kg} / \mathrm{m}^{2}$. In view of results, some effective measures of controlling haze pollution were put forward to reduce the construction dust emission and the environment load.

\section{Introduction}

In recent years, the issue of haze in China has become more and more important and has become the focus of current environmental governance. The main material of haze pollution is atmospheric suspended particulate matter. Building dust as one of the main sources of atmospheric suspended particulates, is closely related to the concentration of atmospheric suspended particulates. The research shows that the contribution of building dust to concentration of PM2.5 and PM10 is more than $10 \%{ }^{[1-2]}$; Huang Yuhu and other scholars did a series of studies of dust emissions at the construction stage and the demolition stage ${ }^{[3]}$; Zhang Lili obtained the dust removal coefficient at the existing building demolition stage based on the dust diffusion model ${ }^{[4]}$. At present, most of research focuses on the emission of dust from the construction stage and the dismantling stage. The research on the construction dust emission from the perspective of life cycle evaluation is relatively insufficient ${ }^{[5]}$. With the establishment of the green building evaluation system, the life cycle assessment (LCA) method is used to quantitatively analyze the input-output material flow in the whole life cycle of the building, and it can clearly show the building dust at all stages of the building life cycle emissions.

Software of SimaPro, in the paper, was used to quantitatively analyze the dust emission of frame structure and the frame shear structure in the whole life cycle, Based on the life cycle assessment method and results of comparison, the studies summarized the characteristics and differences of the dust emission in the residential buildings during the life cycle of the two different structures and then gives specific measures to reduce the emission of building dust. 


\section{Project case}

With the demolition of the village and construction of new building carrying out in Zhengzhou, the scale of the building is expanding, which increased haze pollution and decrease air quality. Two kinds of residential buildings with different structure forms in Zhengzhou are chosen as the research object. The orientation and function of the buildings are the same, and their design reference period are assumed to be 50 years. Frame structure residential building is marked as case A, Frame shear structure residential building is regarded as case B. Construction area of A and B are respectively $3566.22 \mathrm{~m}^{2}$ and $16266 \mathrm{~m}^{2}$.

\section{Life cycle assessment of residential buildings}

\section{Determination of objectives and scope}

The aims of study is to provide a reference how to decide the building structure In the green angle, so we need to obtain the emissions of case A and B and analyze the same and difference of result.

The scope of the study is based on input-output material flow at the materials production stage, the construction stage, the operation stage and the dismantling stage. In order to obtain more accurate results, The two assumptions were made to avoid uncertainty elements: a) Only the energy is input in the construction stage, the operation stage and the removal stage; b) The functional unit is $1 \mathrm{~m}^{2}$ residential building.

\section{Analysis of life cycle inventory}

(1).The base data source

At present, the domestic research on the life cycle assessment has made great achievements in the Beijing University of Technology, Tsinghua University, Sichuan University and the Chinese Academy of Sciences Ecological Environment Research Center. Among them Beijing University of Technology and Sichuan University have developed the life cycle assessment database and related software. In the paper, the material flow in the building materials and energy production stages ${ }^{[6-10]}$ is mainly obtained from the relevant research of four institutions, and the basic data for raw material is acquired from the SimaPro software database.

(2).The list of four stages in life cycle

Building materials production stage only input the material flow in building materials production process, the other three stages input energy consumption data. The list of material flows in all stage is shown in Table 1.

Table 1. The material flow list and dust emissions at each stage

\begin{tabular}{cccccc}
\hline \multirow{2}{*}{ LCA } & Substance type & \multicolumn{2}{c}{ Input material flow } & \multicolumn{2}{c}{ Emission of dust $(\mathrm{kg})$} \\
& & A & B & A & B \\
\hline \multirow{2}{*}{ Materials } & Steel $(\mathrm{t})$ & 121 & 1093 & 545.79 & 4925.08 \\
production stage $^{(1)}$ & Cement $(\mathrm{t})$ & 132 & 983 & 1627.85 & 12110.09 \\
& Concrete $\left(\mathrm{m}^{3}\right)$ & 1239 & 10384 & 677.84 & 5675.06 \\
& Block $\left(\mathrm{m}^{3}\right)$ & 705 & 2545.16 & 41667.69 & 150271.85 \\
\hline \multirow{2}{*}{ Construction stage $^{(1)}$} & Diesel $(\mathrm{kg})$ & 2367 & 9209 & 2.83 & 11.02 \\
& Gasoline $(\mathrm{kg})$ & 1573 & 6616 & 1.91 & 8.02
\end{tabular}




\begin{tabular}{cccccc} 
& Electricity $(\mathrm{kWh})$ & 38808 & 173353 & 422.38 & 1886.75 \\
\hline \multirow{2}{*}{ Operation stage $^{(2)}$} & Natural gas $(\mathrm{kg})$ & 1859784 & 8482719 & 711.08 & 3239.97 \\
& Electricity(kWh) & 2692496 & 12280830 & 29304.69 & 133524.84 \\
\hline & Diesel(kg) & 2130.3 & 8288.1 & 2.5482711 & 9.91 \\
& Gasoline $(\mathrm{kg})$ & 1415.7 & 5954.4 & 1.716613 & 7.22 \\
Dismantling stage $^{(3)}$ & Electricity $^{(\mathrm{kWh})}$ & 34927.2 & 156017.7 & 380.14203 & 1698.07 \\
& Dust $^{[4]}$ & $/$ & $/$ & 48143.97 & 219591
\end{tabular}

Note: (1)List of materials from the construction unit; (2)Annual Report on China's Building Energy Conservation in 2013 showed unit area of residential construction operation and maintenance phase consumed $10.43 \mathrm{~kg}$ of natural gas and $15.1 \mathrm{kWh}$ of electricity in a year; (3)The National Statistical Yearbook present that the energy consumption during the demolition accounted for $90 \%$ of the energy consumption during the construction stage.

\section{Quantitative analysis of dust emission in Life cycle}

Based on the above list data, Simapro software is used to respectively analyze the case A and case $\mathrm{B}$, and the dust emission in the life cycle of project A and B is obtained as shown in Table 1.The four stages of dust emission is shown in Fig. 1.

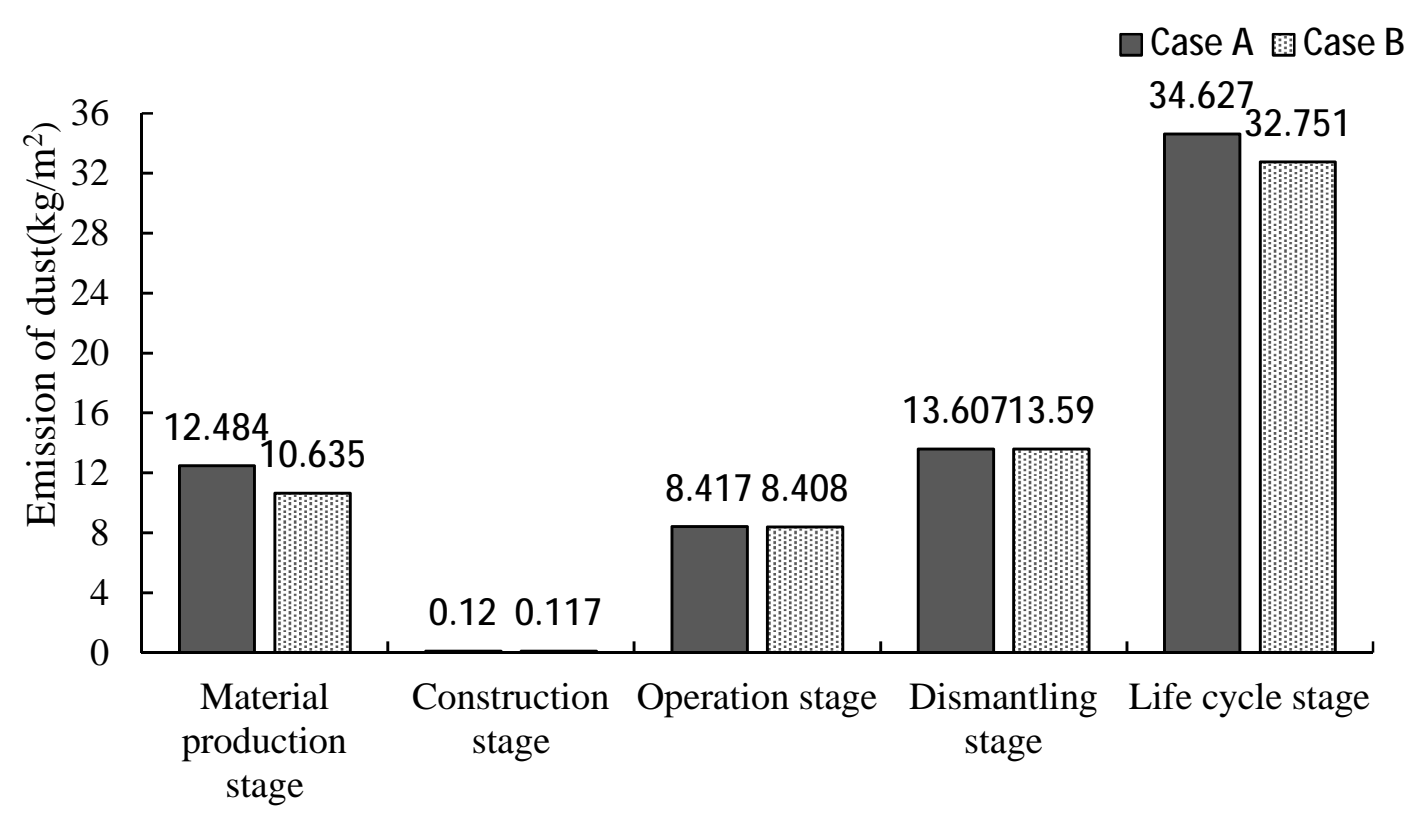

Fig 1. Dust emission in residential buildings with different structures

The dust emission of case A and B respectively are $34.627 \mathrm{~kg} / \mathrm{m}^{2}$ and $32.715 \mathrm{~kg} / \mathrm{m}^{2}$, and the former is higher at all stages than the latter. the dust emission at materials production stage of them exist biggest difference and respectively is $12.484 \mathrm{~kg} / \mathrm{m}^{2}$ and $10.635 \mathrm{~kg} / \mathrm{m}^{2}$, the remaining three stages of dust emissions vary slightly.

In the project, the dust emission at all stages of case $\mathrm{A}$ and case $\mathrm{B}$, both is from the following steps: the dismantling stage, the building material production stage, the operation stage and the construction stage. In general, under the established assumptions, the dust emission at all stages of the residential building during whole life cycle are sorted: Dismantling stage> Building materials production stage $>$ Operation stage $>$ Construction stage. 


\section{Explanation of results}

(1) At the functional conditions of using, dust emissions of $1 \mathrm{~m}^{2}$ frame structure of residential building life cycle is larger than the frame shear structure, mainly resulted by the different of building materials consumption in unit floor area, in which the contribution of cement products is larger proportion.

(2) Whether the frame structure or frame-shear structure of the residential building life cycle, dust emissions at all stages of the building are following from large to small: removal stage, building materials production stage, operation and maintenance stage, construction stage. Among them, dust emissions at the demolition stage is mainly produced by input of dust,so in the demolition process we could cover the dust cloth and continuous sprinkler to reduce dust emissions. The dust at the building materials production stage is mainly caused by the production of cement products, so it is effective measures that we alternate materials in the construction of residential buildings to reduce the consumption of cement products and reduce dust emission; the dust source at the operation stage and the construction stage are the electricity consumption, the government and enterprises should optimize structure of the power supply to reduce the thermal power supply.

\section{Conclusions}

Based on the above analysis, If the frame structure and frame shear structure could meet the safety requirements we should give priority to choosing the frame fear structure, The results of the study have some reference value for the research of dust emission in other similar buildings.

The study of dust emissions in the life cycle is a complex task that involves a large amount of basic data to support. In the future work, the basic data collection should be strengthened to provide reliable data for relevant research.

\section{References}

[1] Zhang Wenting, Wang Xuesong, Liu Zhaorong, et al. Construction Fugitive PM10Emission and ItsInfluences on Air Quality in Guiyang[J], Acta Scientiarum Naturalium Universitatis Pekinensis, 2010, 46(02):258-264.

[2] Huang Jianguang. Emission of PM2.5 in Building Dust and Its Impact on Environment[J], Environment and LIfe, 2014(16): 141-142.

[3] Huang Yuhu, Fan Shoulin, Qin Jianping, et al. Study on Dust Pollution Emission from Beijing Construction Demolition Project[M], Beijing Green Olympics Environmental Protection Technology and Development Symposium Proceedings in 2005, Beijing, 2005:291-298.

[4] Zhang Lili, Xu Yijun, Wang Kun, et al. Calculation Preventation and Control of Construction Dust Emission-With Zhengzhou City of Henan Province as Example[J], Henan Science, 2012, 30(7):961-963.

[5] Bian Yadong, Dai Yanru, Li Qingwen, et al. Study on the Dust Emission in the Life Cycle of Residential Buildings[J], Journal of Zhong yuan university of technology, 2016, 27(6):78-81.

[6] Wang Lafang Zhang Lisha. Life Cycle Assessment of Environmental Impacts For the Whole Steel Production Process[J]. China Population, and Environmental, 2012, 22(11):239-244.

[7] Jiang Rui, Wang Hongtao. Life Cycle Assessment of China 's Cement Industry[J]. Chemical Engineering \& Equipment, 2010,4:183-187. 
[8] Li Xiaodong, Wang Shuai Kong, Xiangqin, et al. Life Cycle Assessment of environmental impacts of ready mixed concrete[J]. China civil engineering journal, 2011, 44(01):132-138.

[9] China Building Materials Inspection and Certification Group. Green building materials selection technology [M]. Beijing:Chemical Industry Press,2015:134-135.

[10] Ding Ning, Yang Jianxin. Life cycle inventory analysis of fossil energy in China. China Environmental Science, 2015, 35(05):1592-1600. 